\title{
The Role of Gender in the Use of Metacognitive Awareness Reading Strategies among Biology Students
}

\author{
Arsaythamby Veloo ${ }^{1}$, Mariam A Rani ${ }^{2} \&$ Hariharan, K. ${ }^{1}$ \\ ${ }^{1}$ School of Education and Modern Languages, University Utara Malaysia, Malaysia (UUM), Malaysia \\ ${ }^{2}$ Kedah Matriculation College, Ministry of Education, Malaysia, Changlun, Malaysia \\ Correspondence: Arsaythamby Veloo, School of Education and Modern Languages, University Utara Malaysia, \\ 06010 Sintok, Kedah, Malaysia. E-mail: arsay@uum.edu.my
}

Received: September 7, 2014

Accepted: October 9, 2014 Online Published: December 2, 2014

doi:10.5539/ass.v11n1p67

URL: http://dx.doi.org/10.5539/ass.v11n1p67

\begin{abstract}
Metacognitive Awareness Reading Strategies used by students while reading academic material is one of the factors that lead to students' future academic achievement. This study aims to determine the association between gender and gender differences in the perceived use of Metacognitive Awareness Reading Strategies (Global, Problem-Solving \& Support Reading strategies) among Biology students in a Matriculation College situated in State of Kedah, Malaysia. In this study, 318 Matriculation College students participated, in which 97 male students and 221 female students studied Biology as one of the subjects. They rated their own perceived use level of Metacognitive Awareness Reading Strategies using Metacognitive Awareness of Reading Strategies Inventory (MARSI) adapted from Mokhtari and Reichard (2002). The findings show that female students use Metacognitive Awareness Reading Strategies more frequently compared to male students while reading academic materials. The findings show that students apply problem-solving strategies the most compared to the other metacognitive reading strategies, while the least used strategy is the global reading strategy. However, there are no significant difference between males and females for both these strategies. In comparison, male and female students differ in the application of Support Reading Strategies, where more females use the strategies compared to males. Students themselves should learn Metacognitive Awareness Reading Strategies and apply them in their Biology reading. Global reading strategies, too, should be given more attention as this is the least used strategy. A more balanced use of all the metacognitive strategies would help students to improve their level of achievement as each strategy has its own strengths. Future research should investigate the ways to nurture metacognitive skills in reading as one of the strategies to improve reading comprehension and future performance in Biology.
\end{abstract}

Keywords: metacognitive, global reading strategies, problem-solving reading strategies, support reading strategies, biology achievement

\section{Introduction}

Most of the people are able to read since at a very young age, not all readers have the skill to read effectively. Without skill, people can "read" but nothing will remain in their mind or memory so there will be no improvement on their previous knowledge but only a waste of time and energy. In this case, students have to read a lot to gain knowledge and get ideas about their learning, so they need good reading skills to mind their own learning and cognitive processes during reading to enhance learning and memory.

Apart from giving full attention during lectures to identify main ideas in the content, Biology students must read reference books to enhance their knowledge and understand the subject matter. Reading is important to relate the content with the real world and later in their career. This is critical because what is learnt must be understood thoroughly before this knowledge can be applied in other situations. (Ormrod, 2008). In addition, the ability to read profoundly is very important because they will influence academic achievement (Kuo-En, Yu-Ju, Chien-Mei, \& Yao-Ting, 2010). Although the contents in Biology are divided into topics, they are interrelated and need a meaningful understanding. Therefore, students must have a deep understanding of one particular concept to better understand other concepts in subsequent topics or chapters. 


\subsection{Problem Statement}

Jamian (2011) studied the problems in Malay reading and writing among primary students in rural areas in Malaysia. He found that the students failed to comprehend the information presented and the meaning of sentences in the text they read. Md Nor and Syed Muammar Billah (2012) in a study towards secondary school students in Biology subtopic Photosynthesis found that students understanding level in Photosynthesis in a moderate ranking from five level of understanding. Students with poor comprehension claimed that they studied hard for a test but then got poor grades. There are also students who claimed that they do not understand what they read and others claimed that they read a lot and think they "know" the content of books they read but then the teacher detected misconceptions in their writing (Ormrod, 2008).

\subsection{Metacognitive Reading Strategies}

A study by Saemah et al. (2011) stated that most of the students support and encourage the use of metacognitive strategies in the classroom. Considering the importance of reading comprehension, a number of researchers built inventories that measures metacognition including studies towards English as a second language (ESL) students (Mokhtari \& Sheorey, 2002). The earlier version of Schmitt (1990) was a 25-items of multiple choice questionnaire built for teachers use to evaluate middle and upper elementary students' knowledge of strategic reading processes. For almost the same purpose, Mokhtari and Reichard (2002) proposed a 30-item questionnaire that uses to increase students' metacognitive awareness during reading and the results will help in enhance assessment, planning instruction, or conducting classroom or clinical research.

In this study, the researcher defined application of Metacognitive Awareness Reading Strategies as a self-report of the respondents in the extent to which they use the reading strategies based on metacognition as suggested in MARSI by Mokhtari and Reichard (2002). This questionnaire had been categorised by the proposers into three sub strategies or factors that are Global Reading Strategies, Problem-Solving Strategies and Support Reading Strategies.

\section{Literature Review}

\subsection{Global Reading Strategies}

This first subcategory represented a set of reading strategies that oriented toward a global analysis of the text. These strategies help readers in generalising, and can be thought of as intentional reading strategies aimed at setting stage of reading (Mokhtari \& Reichard, 2002). Global strategies that use by readers is grounded in think-aloud study (Pressley \& Afflerbach, 1995) in their book that discussed about readers behaviors as they read a material. Readers engage in behaviors such as previewing text and skimming before they read as well as during-reading behavior such as adjusting expectations.

\subsection{Problem-Solving Strategies}

This second factor in MARSI is oriented around strategies applied for solving problems faced when text becomes difficult to understand. The strategy includes reading slowly and carefully, adjusting reading speed according to text difficulty, paying close attention when facing problem to understand the text, pausing to reflect the text, reread, visualize the text, read aloud and guessing the meaning of unknown words. These strategies provide readers with action plans that help readers to navigate through text skilfully. These localised, focused problem-solving or repair strategies will be used when problems arise in understanding the information in the text (Mokhtari \& Reichard, 2002). These problem-solving strategies in MARSI supported the work by Pressley and Afflerbach (1995) who reported that successful readers monitored their comprehension and solved problems that arose while they read.

\subsection{Support Reading Strategies}

The third subcategory (Support Reading Strategies) is oriented around the use of outside reference material, the initiative of taking notes while reading, and other practical strategies that are described as functional or support strategies. These strategies provide useful support mechanisms at sustaining responses to reading such as the use of dictionaries (Mokhtari \& Reichard, 2002). Fenfang (2010) studied the English reading strategies using the same questionnaire among by senior middle school and found that the majority of students used Problem-Solving Strategies, followed by Global Reading Strategies and Support Reading Strategies.

2.4 Association between Gender and Perceived Use of Metacognitive Awareness Reading Strategies among Biology Students in Matriculation College

Logan and Johnston (2010) reported that males and females performance on reading comprehension may depend on a few factors. One of the factors is the type of reading instruction and learning environment to which males or 
females may be more suited. Fenfang (2010) found that females are more careful and considerate in their reading compared to males who are more adventurous and bolder due to differences in nurturance given to both genders in their culture.

\subsection{Difference in the Perceived Use of Metacognitive Awareness Reading Strategies Based on Gender}

A study by Ozkan and Hatice (2013) showed that metacognitive awareness of high school students differed based on academic and individual variables. Gender differences in reading ability and attitudes were intentionally discussed by Logan and Johnston $(2009,2010)$. Logan and Johnston $(2009,2010)$ stated that there are enormous variations in both male and female reading and cognitive abilities. Findings by Young and Oxford (1997) and Yenilmez, Sungur, and Tekkaya (2006) who studied students' achievement regarding photosynthesis and respiration in plants showed gender differences, though it was not large. A related study by Berkant (2009) showed that there is no difference between male and female causal thinking abilities that contribute to reading comprehension and academic achievement. Based on the same questionnaire, other researchers found that females show higher use of reading strategies than males in the combined sub-categories (Fenfang, 2010) as well as in each individual category (Fenfang, 2010; Cantrell \& Carter, 2009).

\subsection{Research Objectives}

1.To determine the association of the perceived use of Metacognitive Awareness Reading Strategies (Global, Problem-Solving and Support Reading Strategies) and gender among Biology students in a Matriculation College.

2. To determine gender differences in the perceived use of Metacognitive Awareness Reading Strategies (Global, Problem-Solving and Support Reading Strategies) among Biology students in a Matriculation College.

\section{Method}

\subsection{Population and Sample}

There are 1300 students who study Biology as one of the subjects for their program at the Matriculation College situated in State of Kedah, Malaysia. From this population, 1013 (78\%) are female students whereas 287 (22\%) are male. The total sample size was 318 students (Krejcie \& Morgan, 1970). Participants were selected based on random sampling with a total of $97(30 \%)$ males and $221(70 \%)$ females.

\subsection{Research Instrument}

The students rated their own level of metacognitive strategies used while reading based on MARSI adapted from Mokhtari and Reichard (2002). The instrument has high reliability to measure students' reading strategy use with a Cronbach's alpha coefficient of 0.93 for the entire scale. The researcher gave a copy of these reading strategies to each of the students as an exposure for them at the beginning of the semester. MARSI measures three sub strategies, that is, Global Reading Strategies, Problem-Solving Strategies and Problem-Solving Strategies. These three types of reading strategies interact with each other and have influence on text comprehension.

Global Reading Strategies are represented by 13 items (1, 3, 4, 7, 10, 14, 17, 19, 22, 23, 25, 26, 29) consist of a set of reading strategies oriented toward a global analysis of text read. Examples include "setting purpose while reading, guessing what the material is about, skimming the text to aware with text characteristic". These strategies can be said of as generalized, intentional reading strategies aimed at the beginning stage of reading.

Problem-Solving Strategies consists of 8 items $(8,11,13,16,18,21,27,30)$ that represent strategies to solve problems that develop in the attempt to understand textual information. Examples of these strategies include " pay closer attention when text become difficult, pause the reading to think about the material, re-read for better understanding". Support Reading Strategies contain 9 items $(2,5,6,9,12,15,20,24,28)$ and primarily ascertain whether the reader uses outside reference materials, takes notes, underlines or circles important information and other practical strategies such as discuss with others. These strategies are used to know the support mechanisms use while reading.

This questionnaire had been administered within one week of the end of the semester. The researcher gave instructions and administered the questionnaire during the students' free time. After explaining the purpose of the inventory, the researcher asked the students to read each statement and rate how often they use the strategies on a scale ranging from 1 (I never do this) to 5 (I always do this). Participants were reminded that their responses were to refer to the strategies they used when reading Biology school-related material only during that semester. The researcher did this because the data would be correlated with the particular semester examination results. They were also encouraged to respond honestly to each statement in the inventory, and to ask questions about 
any aspect of the inventory that they did not understand. Students were given 15 minutes to answer the questionnaire.

\subsection{Data Collection and Analysis}

The participants had been asked to rate their metacognitive awareness and perceived use of reading strategies during reading in the MARSI survey questionnaire. The data collection was carried out within a few sessions during students' free time in the classroom. Students' performance was presumed to result from the metacognition and strategies applied during the reading of Biology books. Thus, Biology results obtained at the end of the same semester were used because it is assumed that students' learning by reading will help them to perform in the examination. The examination includes all the topics learned in the whole semester. The data is analysed using Statistical Package for the Social Sciences (SPSS) version 20. In this study, data analysed by using Independent-Samples t-test and Chi Squared test. In addition to the t-test, the effect size $(d)$ is also used to explain the results in terms of effect size. Cohen (1988) suggested three categories of effect-size, that is, smalleffect size $(d=0.20)$, medium-effect size $(d=0.50)$, and large-effect size $(d=0.80)$.

\section{Results}

\subsection{Association between Gender and Metacognitive Awareness Reading Strategies}

Table 1 shows the association between gender and the reading strategies that they prefer while reading Biology reference books. The Chi-Square test was significant $\left(\chi^{2}(2)=6.22, p<.05\right)$ and it shows that there is an association between gender and reading strategies among the students. A comparison between the 3 Metacognitive Awareness Reading Strategies in Biology show that 212 prefer the problem-solving strategy while 69 preferred the support reading strategy and 31 of the students preferred the global reading strategy. Among the three sub factors in Metacognitive Awareness Reading Strategies for reading Biology books (Table 1), both male and female students prefer to use Problem-Solving Strategies which results in the highest usage that is 212 students. From this total, 139 female students prefer problem-solving reading strategies compared to 73 male students. Although both genders prefer the same strategy, female students use Problem-Solving Strategies more than male students. The second highest reading strategy used by the student is the support reading strategy. From a total of 69 students who use this strategy, 56 are female students while 13 are male. The least used strategy as a whole is the global reading strategy. From a total of 31 students who use this strategy, 20 are female students while 11 are male.

Table 1. Results of chi squared test for gender and reading strategies among Biology students in Matriculation college

\begin{tabular}{lccc}
\hline & $\begin{array}{c}\text { Global } \\
\text { Reading strategy }\end{array}$ & $\begin{array}{c}\text { Problem-solving } \\
\text { Reading strategy }\end{array}$ & $\begin{array}{c}\text { Support } \\
\text { Reading strategy }\end{array}$ \\
\cline { 2 - 4 } & $\mathrm{N}$ & $\mathrm{N}(\%)$ & $\mathrm{N}$ \\
\hline Male & 11 & 73 & 13 \\
Female & 20 & 139 & 56 \\
Total $(\%)$ & 31 & 212 & 69 \\
\hline
\end{tabular}

$\frac{\text { Total }(\%)}{\chi^{2}=6.22, p<.05}$

\subsection{Gender Differences in the Use of Metacognitive Awareness Reading Strategies}

Results for the overall Metacognitive Awareness Reading Strategies show that there is a difference among male and female students. More females use Metacognitive Awareness Reading Strategies in Biology compared to males. The mean score for Metacognitive Reading Strategy is higher for female students (3.58) compared to male students (3.40). Independent samples t-test between gender and Metacognitive Awareness Reading Strategies is significant ( $\mathrm{t}(310)=-1.98, \mathrm{p}=.05, d=-0.35)$ and effect size is medium (Table 2).

The findings also show significant differences between males and females for the Support Reading Strategies. More females use Support Reading Strategies in their Biology compared to males. The mean score for Support Reading Strategy is higher for female students (3.51) when compared to the male students (3.24). Independent samples t-test between gender and Support Reading Strategies is significant $(\mathrm{t}(310)=-3.71, \mathrm{p}<.05, d=-0.45)$ and effect size is medium (Table 2).

There is no difference between male and female students in the use of Global Reading Strategies and Problem-Solving Reading Strategies. The Independent sample t-test shows that there is no significant difference 
$(\mathrm{t}(310)=-1.15, \mathrm{p}>.05, d=-0.04)$ and effect size is small in Global Reading Strategies. The Independent sample t-test also shows that there is no significant difference $(\mathrm{t}(310)=-0.08, \mathrm{p}>.05, d=-0.12)$ and effect size is small in Problem-Solving Reading Strategies (Table 2).

Table 2. Results of independent samples t-test to show the difference in the use of metacognitive awareness reading strategies between male and female students

\begin{tabular}{cccccccc}
\hline Reading strategy & Gender & N & Mean & SD & Df & t & p \\
\hline \multirow{2}{*}{ Metacognitive } & Male & 97 & 3.40 & .52 & 310 & -1.98 & $0.05^{*}$ \\
& Female & 221 & 3.58 & .51 & & & \\
\hline \multirow{2}{*}{ Global } & Male & 97 & 3.34 & .57 & 310 & -1.15 & 0.25 \\
& Female & 221 & 3.42 & .58 & & & \\
\hline \multirow{2}{*}{ Problem solving } & Male & 97 & 3.80 & .61 & 310 & -0.08 & 0.94 \\
& Female & 221 & 3.81 & .59 & & & \\
\hline \multirow{2}{*}{ Support } & Male & 97 & 3.24 & .64 & 310 & -3.71 & $0.00^{*}$ \\
& Female & 221 & 3.51 & .58 & & & \\
\hline
\end{tabular}

$\mathrm{p}>.05,{ }^{*} \mathrm{p} \leq .05$

\section{Discussion and Conclusion}

\subsection{Association between Gender and Metacognitive Awareness Reading Strategies}

Among the three sub factors in Metacognitive Reading Strategies, both male and female students preferred to use Problem-Solving Strategies. A comparison between male and female students shows that female students use Problem-Solving Strategies more than male students. This finding contradicts the review by Cantrell and Carter (2009) in which male students use Problem-Solving Strategies more than female students. Both male and female students use Global Reading Strategies the least. Female students apply the Global Reading Strategies more than males. This result is contradicts by the research by Fenfang (2010) that found that males are more adventurous and bolder compared to females which are more careful and considerate in their reading. By that reason, males are more ready to explore the text as shown in Global Reading Strategies. This explanation will support the report of Logan and Johnston (2010) that is males and females performance on reading comprehension depends on few factors including they are more suitable in different type of reading instruction and learning environment. This finding is also in line with the study by Saemah et al. (2013) in which metacognitive strategy (including awareness of metacognition) in the classroom is very important in learning especially in Biology.

\subsection{Difference in the Use of Metacognitive Awareness Reading Strategies Based on Gender of Biology Students in Matriculation College}

The results show that the female students use more of the Support Reading Strategies in Biology than males. Although there is a gender difference in Metacognitive Awareness Reading Strategies, the results show that more females used Support Reading Strategies in their Biology reading compared to males. It proves that males and females do differ in some aspects and it is supported by Logan and Johnston (2010) that stated there is enormous variation in both male and female cognitive abilities. This argument is strengthened by the same researcher, Logan and Johnston (2009) who reported that females had a more positive attitude to reading and school. However, this finding contradicts Berkant's (2009) study that showed that causal thinking as a component of metacognition and gender was not a factor.

Generally, not all the subscales show gender differences as reported by Fenfang (2010) and Ozkan and Hatice (2013). These findings are supported by Yenilmez et al.'s (2006) research on Biology achievement in two topics, that is, photosynthesis and respiration in plant achievement. Metacognitive Awareness Reading Strategies used by students while reading academic material is one of the factors that lead to students' future academic achievement. In this study most of the students apply problem-solving strategies compared to the other metacognitive reading strategies, but there is no significant difference between males and females. Global reading strategies are the least used strategy among the metacognitive reading strategies, with the females using this strategy more than the males.

\subsection{Implication of Research Findings}

The college committee should offer Metacognitive Awareness Reading Strategies courses for students. All the metacognitive strategies have their advantages to enhance reading and a more balanced approach would help 
students to use their limited time for reading more efficiently. Courses can be designed to create awareness of the practical applications of the three skills during the reading process. If teachers are trained to use these skills, they can share these skills with their students during Biology classes or other classes that require reading activities. Strategies taught need to be reinforced continually in Biology texts so that students are able to use the strategies effectively. This will enhance efficient use of time in the reading of texts, and improve comprehension as Biology requires extensive and intensive reading throughout the duration of the course.

Biology teachers must understand students' reading processes and identify comprehension issues so that they can offer effective reading strategies that help students retain reading information longer. Therefore, teachers have to learn how to practice reading strategy instruction in Biology classrooms so that students are able to better manage voluminous texts.

Students should take the initiative to learn reading strategies and apply them consistently in their reading. When reading strategies are applied, students will be able to monitor their own reading comprehension and adopt Problem-solving Strategies more readily whenever they encounter problems in understanding the text. Readers could also focus on strategies categorized under Global Reading Strategies as this research found that these strategies have a positive impact on reading Biology texts. Additionally, gender differences provide useful input on the type of reading strategies applied by male and female students and the type of reading skills that Biology teachers need to impart to them.

\subsection{Recommendations for Further Research}

There are many possible changes to the study design that might have contributed to more insights on the theory. The major concern is the sample used in this study. This study only involves one college and only focused on differences between genders. The researcher recommends that future research considers performing the research using a large number of colleges and compare different ages or ethnic groups. Although this research studied about gender, there were imbalances in the number of male and female participants. The researcher recommends that future research puts more effort in balancing the proportion of males and females.

This study is confined to Biology students and it is recommended that future research compares results among other participants and examine the results. The recent study only examined Metacognitive Reading Strategies. Future research can consider different reading strategies or compare them to find the best strategies. Future research could also look into longitudinal studies and use the mixed method. The current study is rather limited as it uses a quantitative approach over a short duration of time. This alternative approach could provide richer data to complement the quantitative findings and give a more holistic picture about the readers' type and level of strategies application.

\subsection{Conclusion}

The study illuminates several important points regarding reading strategies in Biology. The result shows that most of the students used Problem-Solving Strategies, followed by Support and Global Reading Strategies. Both male and female students used Problem-Solving Strategies the most and Global Reading Strategies the least. Males and females only differ in the usage of Support Reading Strategies in which more females used the strategies compared to males. Seeing the importance of students' perceived use of strategies and metacognition while reading, researchers could study more about how to nurture metacognition during learning as well as in daily life. A more balanced use of all the metacognitive strategies would help students to improve their level of achievement as each strategy has its own strengths Teachers, too, have to understand these skills well and adopt these strategies in their classroom instruction. This is important so that students will be aware of these techniques and apply them in their reading and learning. By this, it is hoped that uses of Metacognitive Awareness Reading Strategies will promote active and meaningful learning among students thus enhancing students' academic achievement.

\section{References}

Berkant, H. G. (2009). An investigation of students' meaningful causal abilities in terms of academic achievement, reading comprehension and gender. Educational Sciences: Theory \& Practice, 9(3), 1149-1165.

Cantrell, S. C., \& Carter, J. C. (2009). Relationships among learner characteristics and adolescents' perceptions about reading strategy use. Reading Psychology, 30(3), 195-224. http://dx.doi.org/10.1080/027027108 02275397

Cohen, J. (1988). Statistical power analysis for the behavioral sciences (2nd ed.). Hillsdale, NJ: Erbaum. 
Fenfang, L. (2010). A study of English reading strategies used by senior middle school students. Asian Social Science, 6(10), 184-192.

Jamian, A. R. (2011). Permasalahan kemahiran membaca dan menulis Bahasa Melayu murid-murid sekolah rendah di luar bandar. Malay Language Education Journal, 1(1), 1-12.

Krejcie, R. V., \& Morgan, D. W. (1970). Determining sample size for research activities. Educational and Psychological Measurement, 30(3), 607-610.

Kuo-En, C., Yu-Ju, L., Chien-Mei, C., \& Yao-Ting, S. (2010). Mobile-device supported strategy for Chinese reading comprehension. Innovations in Education \& Teaching International, 47(1), 69-84. http://dx.doi.org/10.1080/14703290903525853.

Logan, S., \& Johnston, R. (2009). Gender differences in reading ability and attitudes: Examining where these differences lie. Journal of Research in Reading, 32(2), 199-214. http://dx.doi.org/10.1111/j.14679817.2008.01389.x

Logan, S., \& Johnston, R. (2010). Investigating gender differences in reading. Educational Review, 62(2), 175-187. http://dx.doi.org/10.1080/00131911003637006

Md Nor Bakar, \& Syed Muammar Billah Syed Mohamad. (2012). Masalah pembelajaran pelajar sekolah menengah dalam matapelajaran sains tingkatan 2 tajuk: fotosintesis. Retrieved November 2, 2012, from http://eprints.utm.my/10944/1/Masalah_Pembelajaran_Pelajar_Sekolah_Menengah_Dalam_Mata_Pelajaran _Sains_Tingkatan_2_Tajuk.pdf.

Mokhtari, K., \& Reichard, C. A. (2002). Assessing students' metacognitive awareness of reading Strategies. Journal of Educational Psychology, 94(2), 249-259. http://dx.doi.org/10.1037//0022-0663.94.2.249

Mokhtari, K., \& Sheorey, R. (2002). Measuring ESL students' awareness of reading strategies. Journal of Developmental Education, 25(3), 2-10.

Ormrod, J. E. (2008). Human Learning. New Jersey: Prentice Hall.

Ozkan, C., \& Hatice, O. (2013). Investigating science high school students' metacognitive awareness and self-efficacy perceptions with some respect to the some individual and academic variables. International Journal of Human Science, 10(2), 246-259.

Pressley, M., \& Afflerbach, P. (1995). Verbal protocols of reading: The nature of constructively responsive reading. Hillsdale, NJ: Erlbaum.

Saemah, R., Ruhizan, M. Y., Kamaruzaman, J. Siti Fatimah, M. Y., Ruslin, A., Zuria, M., ..., Shahlan, S. (2013). Metacognitive Strategies and expertise in learning. World Applied Sciences Journal, 13(4), 645-650.

Schmitt, M. C. (1990). A questionnaire to measure children's awareness of strategies reading processes. The Reading Teacher, 43(7), 454-461.

Yenilmez, A., Sungur, S., \& Tekkaya, C. (2006). Students' achievement in relation to reasoning ability, prior knowledge and gender. Research in Science \& Technological Education, 24(1), 129-138. http://dx.doi.org/10.1080/02635140500485498

Young, D. J., \& Oxford, R. (1997). A gender-related analysis of strategies used to process written input in the native language and a foreign language. Applied Language Learning, 8(1), 43-73.

\section{Copyrights}

Copyright for this article is retained by the author(s), with first publication rights granted to the journal.

This is an open-access article distributed under the terms and conditions of the Creative Commons Attribution license (http://creativecommons.org/licenses/by/3.0/). 